\title{
Role of incubation environment in determining thermal tolerance of sea turtle hatchlings
}

\author{
Christopher R. Gatto*, Bill Matthews, Richard D. Reina \\ School of Biological Sciences, Monash University, Clayton, Victoria 3800, Australia
}

\begin{abstract}
Warming global temperatures are predicted to reduce population viability in many oviparous ectothermic taxa, with increased embryonic mortality likely to be a main cause. While research on embryonic upper thermal limits is extensive, sea turtle hatchling thermal tolerance has received less attention and our understanding of how incubation conditions influence hatchling thermal tolerance is limited. Here, we report green turtle Chelonia mydas hatchling hydration and thermal tolerance following incubation in dry and wet conditions. We used packed cell volume and total protein as indicators of hydration and measured the critical thermal maximum $\left(\mathrm{CT}_{\max }\right)$ of hatchlings in air. Neither hydration nor thermal tolerance was directly influenced by moisture treatment. However, hatchlings from moister nests had longer incubation durations (wet: $60.11 \mathrm{~d}$ vs. dry: $54.86 \mathrm{~d}$ ), and, using incubation duration as a proxy for incubation temperature, hatchlings from cooler nests had significantly lower $\mathrm{CT}_{\max }$ (wet: $39.84^{\circ} \mathrm{C}$ vs. dry: $40.51^{\circ} \mathrm{C}$ ). Thus, despite not directly influencing thermal tolerance, moisture treatment influenced nest temperature indirectly; hatchlings that experienced warmer conditions in dry nests had a higher thermal tolerance than hatchlings from cooler and wetter nests. Ectothermic neonates may have greater plasticity in their thermal tolerance than previously thought, but their ability to adapt to increasing temperature is likely limited. Additionally, common management techniques to reduce nest temperatures, such as watering and shading nests, may only reduce embryonic mortality at the cost of decreased hatchling thermal tolerance and increased hatchling mortality during emergence. Nesting-site management interventions designed to reduce embryonic mortality will need to consider mitigation of the possible effects of those interventions on hatchling mortality.
\end{abstract}

KEY WORDS: Critical thermal maximum - Thermal tolerance - Moisture - Temperature . Hydration $\cdot$ Green turtle $\cdot$ Chelonia mydas $\cdot$ Hatchling

\section{INTRODUCTION}

Environmental factors, such as temperature, moisture, oxygen concentration and salinity, influence multiple traits and phenotypes in a variety of taxa (Caut et al. 2010, Bower et al. 2013). These effects can be long lasting (Elphick \& Shine 1998, Freedberg et al. 2004), and when environmental conditions affect large enough areas of a species' nesting habitat, these environmental factors can significantly affect species at the population level (Santidrián Tomillo et al. 2012, Booth et al. 2020).

\footnotetext{
${ }^{*}$ Corresponding author: christopher.gatto@monash.edu
}

Research into the effects of nest conditions has been extensive in reptiles, particularly sea turtles. Sea turtles provide no parental care, and individuals lay multiple nests within several consecutive months, every few years (Reina et al. 2002). Thus, developing embryos experience considerable temporal variation in incubation conditions, in addition to spatial variation in the microclimate within the nest (Wallace et al. 2004). This variation has important implications for hatchling survival (Burgess et al. 2006, Cavallo et al. 2015). Many studies have investigated temperature effects, showing that warmer nests produce higher

() The authors 2021. Open Access under Creative Commons by Attribution Licence. Use, distribution and reproduction are unrestricted. Authors and original publication must be credited. 
proportions of females (Godley et al. 2002, Godfrey \& Mrosovsky 2006) and smaller, weaker sea turtle hatchlings (Fisher et al. 2014, Booth 2017). These smaller hatchlings are less capable of escaping wave zones and are at higher risk of predation; therefore, they are likely to have higher rates of mortality than larger, stronger hatchlings (Booth \& Evans 2011, Cavallo et al. 2015), potentially leading to reduced survival of female hatchlings and more balanced population sex ratios than previously thought. However, persistent production of extremely female-biased primary sex ratios, eventually leading to adult populations with too few males to sustain a population, was thought to be the greatest threat to sea turtle population viability (Fuentes et al. 2010, Booth et al. 2020).

More recent research suggests that the largest threat to sea turtle populations may be embryonic mortality as a result of increased nest temperatures (Laloë et al. 2014, Santidrián Tomillo et al. 2014, 2015). Both laboratory and in situ studies have shown that sea turtle embryonic mortality increases significantly at temperatures above $34^{\circ} \mathrm{C}$ (Valverde et al. 2010, Howard et al. 2014), although some laboratory studies have observed $0 \%$ hatching success at temperatures as low as $32^{\circ} \mathrm{C}$ in leatherback Dermochelys coriacea and loggerhead Caretta caretta turtles (Binckley et al. 1998, Fisher et al. 2014). With sand temperatures regularly exceeding $34^{\circ} \mathrm{C}$ on many nesting beaches globally (Matsuzawa et al. 2002, Valverde et al. 2010), reduced hatchling production is expected to be a major cause of sea turtle population decline (Santidrián Tomillo et al. 2012). The impact of climate change on hatchling recruitment may extend beyond the nest, because high sand temperatures also increase hatchling mortality when dispersing hatchlings overheat as they crawl from nest to ocean. Temperature-driven hatchling mortality events observed in Australia, the USA and Costa Rica are becoming increasingly common and are likely to exacerbate the effects of embryonic mortality within nests (Santidrián Tomillo et al. 2012, Foley 2017, Lodge 2017).

While considerable effort is being made to maximise hatching success on nesting beaches by relocating eggs and increasing shade (Fuentes et al. 2012, Hill et al. 2015), our understanding of how to increase hatchling survival from nest to ocean is limited. This includes understanding which factors influence the thermal tolerance of dispersing hatchlings. Considering the importance of the incubation environment for sea turtle hatchlings (Godfrey \& Mrosovsky 2006, Booth 2017), it is possible that hatchlings incubated under different conditions may have varying tolerances to extreme temperatures.
Here, we investigated the role of incubation moisture concentrations in determining sea turtle hatchling thermal tolerance. We also examined hatchling hydration as a potential mechanism behind any response of thermal tolerance to nest moisture. Hydration influences the thermal tolerance of reptiles (Plummer et al. 2003), with more hydrated individuals being able to tolerate warmer temperatures. We measured hatchling hydration at emergence using packed cell volume and total protein as indicators and then tested the critical thermal maximum $\left(\mathrm{CT}_{\max }\right)$ of the same hatchlings. The $\mathrm{CT}_{\max }$ is the temperature at which the hatchling cannot remove itself from conditions that would lead to death due to locomotor impairment and is an indicator of the thermal tolerance of an individual without negative longterm effects (Lutterschmidt \& Hutchison 1997, Drake \& Spotila 2002). Temperature-driven hatchling mortality, like embryonic mortality, is becoming more frequent and is an emerging threat to sea turtle population viability (Fuentes et al. 2010, Laloë et al. 2014). This study is an initial investigation into the factors that determine hatchling thermal tolerance and highlights potential management strategies to minimise temperature-driven hatchling mortality events on increasingly warming nesting beaches.

\section{MATERIALS AND METHODS}

\subsection{Study sites, dates and species}

This study was conducted at the Lang Tengah Turtle Watch hatchery on Kuala Abang beach, Dungun, Terengganu, Malaysia (4 48' 53.56“ N, $103^{\circ} 25^{\prime} 25.97^{\prime \prime}$ E). The hatchery was located on the beach above the tide line and was built with a thatched roof that was impermeable to rain and shaded the hatchery (Fig. 1). Entire clutches of eggs ( $\mathrm{n}=40$ clutches) were collected from nesting green turtles Chelonia mydas on Kijal beach, $42 \mathrm{~km}$ south of the hatchery, from 6 to 15 May 2018 (first collection, $\mathrm{n}=20$ ) and 1 to 9 June 2018 (second collection, $n=20$ ). All hatchlings used in this study were from the second collection (nests S21-S40). The first collection was part of another study, although we used nest moisture and temperature data from the first collection (nests S1-S20).

\subsection{Egg collection and transport}

Each clutch was collected in a bucket during oviposition, covered in sand, transported to the shaded 


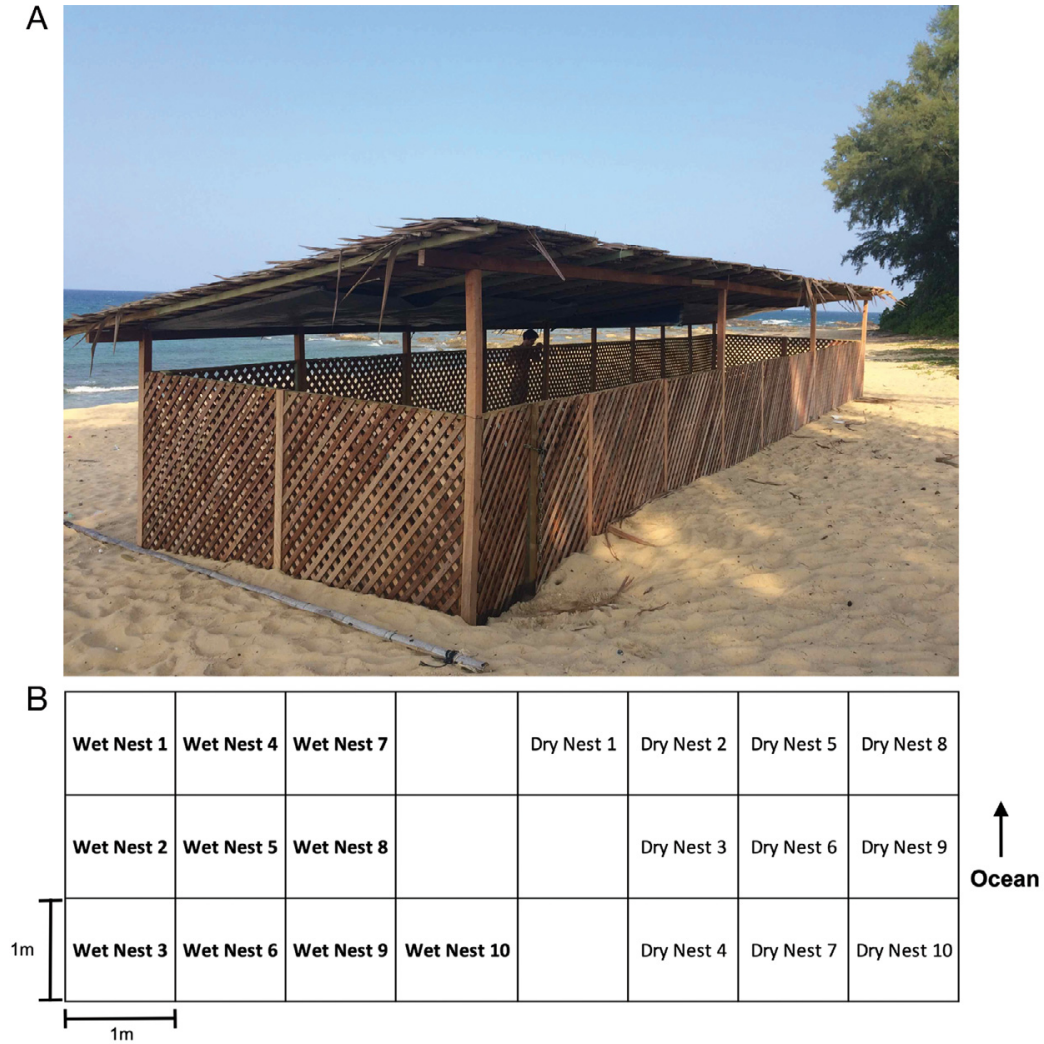

Fig. 1. (A) Shaded Lang Tengah Turtle Watch hatchery, where the eggs in this study were buried. (B) Layout of the hatchery. Each green turtle clutch was buried in a $1 \mathrm{~m}^{2}$ plot, and wet and dry nests were separated by at least 1 empty plot

hatchery and buried within $6 \mathrm{~h}$. Sea turtle embryos break developmental arrest approximately $12 \mathrm{~h}$ postoviposition, so reburying eggs within this time minimises movement-induced mortality (Williamson et al. 2017). Nest chambers were dug in the centre of a $1 \mathrm{~m}^{2}$ plot within the hatchery, to a depth of $70 \mathrm{~cm}$ (Fig. 1). Plots were arranged in a $3 \times 8 \mathrm{~m}$ grid, with wet nests on one side of the grid and dry nests on the other. Wet and dry nests were separated by at least 1 empty plot (Fig. 1).

For each clutch, every third egg was weighed before being placed in the egg chamber. We placed a Thermochron ibutton (Temp-log Australia, DS1921G\#F50, accuracy $\pm 1^{\circ} \mathrm{C}$, resolution $0.5^{\circ} \mathrm{C}$ ) in the centre of 5 wet nests and 5 dry nests to record nest temperature every $3 \mathrm{~h}$ throughout incubation.

\subsection{Nest moisture content}

Prior to collecting the first clutch of eggs, we ran a pilot study to establish an appropriate watering re- gime to maintain our wet nests at $8 \%$ $\mathrm{v} / \mathrm{v}$ moisture and our dry nests at $4 \% \mathrm{v} / \mathrm{v}$ moisture. Moisture content ( $\% \mathrm{v} / \mathrm{v})$ was determined using a soil moisture probe (Pasco ECH $\mathrm{EH}_{2} \mathrm{O}$ EC-5, accuracy $\pm 0.03 \mathrm{~m}^{3}$ $\mathrm{m}^{-3}$, resolution $0.001 \mathrm{~m}^{3} \mathrm{~m}^{-3}$ ) at depths of 35,50 and $70 \mathrm{~cm}$. Using the probe, a calibration curve was created with sand from the hatchery of known moisture content. To create sand of known moisture content, we collected sand from the hatchery and dried it until the mass of the sand stopped decreasing (i.e. all water in the sample had evaporated). We then measured a known volume of the dry sand and added a known volume of water to produce sand of different moisture concentrations.

Once nests were placed in the hatchery, we measured the moisture content of each plot and added the necessary volume of water to maintain the predetermined moisture content daily. The mean standard deviation in moisture content among all 20 nests was $1.02 \%$ v/v. Nest moisture content was measured by digging down in one corner of each $1 \mathrm{~m}^{2}$ plot, and sampling volumetric water content at depths of 40 and $60 \mathrm{~cm}$. We rotated sampling around the plot so that each corner was sampled every fourth day. Once all plots were sampled, we added the necessary amount of water required for each individual plot. In dry nests, sand moisture content naturally stayed above $4 \%$ (range: $4.65-5.5 \%$ ), so no water was added to these nests. Total monthly rainfall during the incubation period was $62.66 \mathrm{~mm}$ in May, $104.87 \mathrm{~mm}$ in June, $96.86 \mathrm{~mm}$ in July and $108.1 \mathrm{~mm}$ in August. We did not detect any spikes in moisture content with rain events.

\subsection{Hatchling morphology}

Upon emergence, we collected all hatchlings from each nest before we selected 5 hatchlings from each nest at random and measured their straight carapace length (SCL) $( \pm 0.01 \mathrm{~mm})$ and straight carapace width $(\mathrm{SCW})( \pm 0.01 \mathrm{~mm})$ using digital callipers (Economy $150 \mathrm{~mm})$, as well as mass $( \pm 0.5 \mathrm{~g})$ using electronic scales (BM series H-3000). Hatchlings were collected as soon as they emerged and were measured within 30 min of collection. On average, hatchling measure- 
ments, hydration measurements and thermal tolerance testing were completed within $120 \mathrm{~min}$ of hatchling collection. Any hatchlings not chosen for testing were released immediately or after sunset for hatchlings that emerged during daylight.

\subsection{Hatchling hydration}

To measure hatchling hydration, we took a $100 \mu \mathrm{l}$ sample of blood from the dorsal external jugular vein at the back of the neck using a 25G needle (Neolus) and $1 \mathrm{ml}$ syringe (Terumo) within $60 \mathrm{~min}$ of emergence from the nest. Blood samples were up to $0.3 \%$ of hatchling total body mass, i.e. less than the $1 \%$ that is considered the maximum safe threshold in reptiles (Mader \& Rudloff 2006). Samples were transferred to heparinised capillary tubes (Livingstone) and centrifuged at $4400 \times g$ for $4 \mathrm{~min}$ (LW Scientific Zipocrit centrifuge). These samples were used to calculate \% packed cell volume (PCV) and total protein $\left(\mathrm{TP}, \pm 2 \mathrm{~g} \mathrm{l}^{-1}\right)$, which was measured from the plasma with a standard refractometer (RHCN-200ATC, NISupply).

\subsection{Hatchling thermal tolerance}

After blood sampling, we tested the $\mathrm{CT}_{\max }$ of each hatchling using a modification of the technique of Drake \& Spotila (2002). First, we measured initial body temperature using a thin, fast-response temperature probe (PASCO PS-2135) inserted a few millimetres into the cloaca. We then placed the hatchling into a bucket lined with a $2 \mathrm{~cm}$ layer of sand and a second temperature probe taped to the bottom of the bucket underneath the sand. Temperature probes were read using a PASCO PASport Xplorer (PS2000) and PASport Quad temperature sensor (Pasco model PS-2143).

We then placed a heat lamp (Exo Terra, Infrared $150 \mathrm{~W}) 20 \mathrm{~cm}$ above the surface of the sand which heated the sand at approximately $1^{\circ} \mathrm{C} \min ^{-1}$. During this time, the hatchling was allowed to freely crawl around the bucket. We continuously observed the hatchling until it began to display 'uncoordinated' movements, at which point we recorded sand temperature. Uncoordinated movements are characterised by sporadic bouts of carapace rubbing with the front flippers, wiggling from side to side and jerky movements (Drake \& Spotila 2002).

We further heated the hatchling until it began to display 'uncontrolled' movements, which are charac- terised by continuous flapping of the front flippers and a general stiffening of the hatchling such that it is unable to crawl (Lutterschmidt \& Hutchison 1997, Drake \& Spotila 2002). When a hatchling displayed these behaviours, we immediately removed it from the bucket, measured its body temperature, designated as its $\mathrm{CT}_{\max }$ recorded sand temperature and recorded the elapsed time.

Once we recorded the $\mathrm{CT}_{\max }$, we placed the hatchling in a container of ambient seawater, where it was monitored continuously until we observed normal swimming behaviours (usually within 30-60 s). All hatchlings recovered and swam normally.

We subsequently held the hatchlings in a bucket lined with sand and covered with a damp cloth until all trials were completed. We then released the hatchlings at the edge of the ocean after sunset.

\subsection{Data analysis}

We compared incubation duration and moisture levels between wet and dry treatments using a Student's $t$-test.

The effect of incubation conditions on morphology, hatchling hydration and thermal tolerance were evaluated using linear mixed effects models with nest moisture content (wet or dry) as the fixed effect and nest ID as the random effect in order to account for maternal effects such as egg mass and unknown differences between nests during incubation. Any remaining variation can be attributed to the incubation conditions.

Relationships between hatchling hydration, thermal tolerance, morphological measurements and incubation duration were also analysed using linear mixed models using nest ID as the random effect. As incubation temperatures increase, embryonic development rates increase and incubation durations decrease, not only in reptiles (Piña et al. 2003, Noble et al. 2018), but also in fish (Murray \& McPhail 1988) and birds (French 1994). Thus, we used incubation duration as a proxy for incubation temperature. For nests where temperature data were collected, we used linear models to investigate the relationship between mean nest temperature and incubation duration.

Models were run in $\mathrm{R}$ version 4.0.2 (R Core Team 2020) using the 'lme4' package (Bates 2015). Our level of significance was 0.05 and p-values were generated using the 'lmerTest' package (Kuznetsova et al. 2017). All models were tested for independence, normality and homogeneity of variance. 


\subsection{Animal ethics and permits}

All experimental procedures were approved the by the Monash University Biological Sciences Animal Ethics Committee (approval BSCI/2018/08) and Terengganu State Fisheries Office (reference SEATRU/ RES/17/01).

\section{RESULTS}

\subsection{Nest moisture content, incubation duration and hatchling morphology}

Mean values for all measurements are provided in Table 1. Mean sand moisture content was significantly lower in dry nests (range: $4.65-5.5 \% \mathrm{v} / \mathrm{v}$ ) than in wet nests $\left(7.5-8.3 \% ; t_{17.985}=24.978, \mathrm{p}<\right.$ $0.001)$. In the 12 total nests $\left(\mathrm{n}_{\text {wet }}=6, \mathrm{n}_{\text {dry }}=6\right)$ in which we recorded temperature over the 2 collection rounds, wet nests were approximately $0.75^{\circ} \mathrm{C}$ cooler than dry nests (Fig. $2 ; t_{9.99}=-3.37, \mathrm{p}=0.007$ ). Hatchlings incubated in wet conditions (55-64 d) took approximately $6 \mathrm{~d}$ longer to hatch than hatchlings incubated in dry conditions (51-58 d; Fig. 2; $\left.t_{17.998}=6.414, \mathrm{p}<0.001\right)$. There was no difference in mass $\left(F_{1,17.735}=1.187, \mathrm{p}=0.291\right), \mathrm{SCL}\left(F_{1,18.184}=\right.$ $0.364, \mathrm{p}=0.554)$ or $\operatorname{SCW}\left(F_{1,18.208}=0.331, \mathrm{p}=0.572\right)$ between hatchlings incubated in wet vs. dry conditions. Nest ID (random effect) explained 84.52, 57.31 and $43.56 \%$ of the variation in mass, SCL and SCW, respectively.

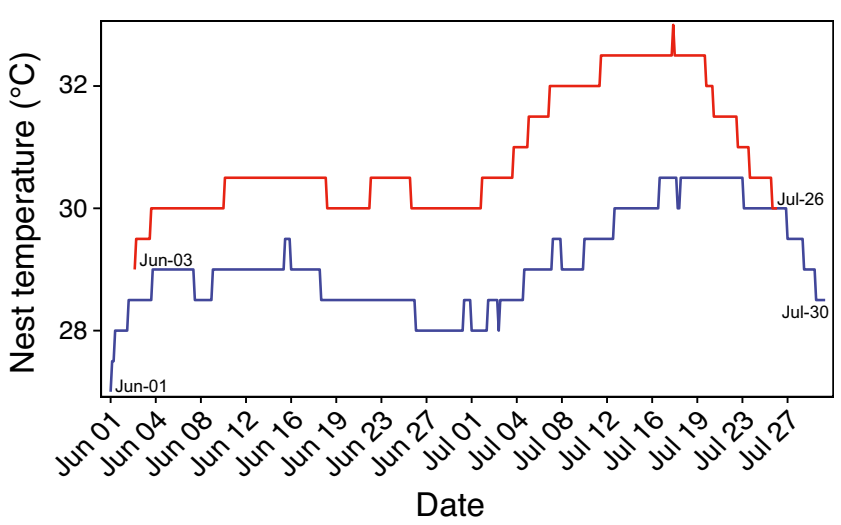

Fig. 2. Green turtle nest temperatures during incubation for nest 21 (blue; wet treatment) laid on 1 June 2018 and for nest 26 (red; dry treatment) laid on 3 June 2018

\subsection{Hatchling hydration}

There was no difference in PCV $\left(F_{1,17.556}=2.257, \mathrm{p}=\right.$ 0.151, Table 1$)$ or TP $\left(F_{1,18.222}<0.001, \mathrm{p}=0.976\right.$, Table 1) between hatchlings incubated in wet or dry conditions. Nest ID explained $30.48 \%$ of the variation in PCV and $49.38 \%$ of the variation in TP. Hatchlings with higher PCV also had higher TP $\left(F_{1,85.359}=8.012\right.$, $p=0.006, R^{2}=0.021$ ), although the relationship was weak. Nest ID explained $40.76 \%$ of the variance.

\subsection{Hatchling thermal tolerance}

When analysing the effect of moisture on thermal tolerance using the specific moisture concentrations

Table 1. Effects of moisture treatment on nest environment, hatchling morphometrics, hydration and thermal tolerance. Values are reported as mean \pm SD. Statistically significant differences between wet and dry incubated hatchlings are highlighted in bold. SCL: straight carapace length; SCW: straight carapace width

\begin{tabular}{|c|c|c|c|}
\hline Measurement & Dry incubation & Wet incubation & Comparison between wet and dry nests \\
\hline Nest moisture content (\% v/v) & $4.98 \pm 0.24$ & $7.89 \pm 0.23$ & $t_{17.985}=24.978, \mathrm{p}<0.001$ \\
\hline Incubation duration (d) & $54.86 \pm 1.87$ & $60.11 \pm 1.63$ & $t_{17.998}=6.414, \mathrm{p}<0.001$ \\
\hline $\mathrm{SCL}(\mathrm{mm})$ & $46.45 \pm 1.92$ & $46.09 \pm 1.75$ & $F_{1,18.184}=0.364, \mathrm{p}=0.554$ \\
\hline $\mathrm{SCW}(\mathrm{mm})$ & $36.05 \pm 1.74$ & $36.33 \pm 1.30$ & $F_{1,18.208}=0.331, \mathrm{p}=0.572$ \\
\hline Mass (g) & $20.97 \pm 2.27$ & $22.17 \pm 1.71$ & $F_{1,17.735}=1.187, \mathrm{p}=0.291$ \\
\hline Packed cell volume (\%) & $32.57 \pm 4.53$ & $30.47 \pm 4.72$ & $F_{1,17.556}=2.257, \mathrm{p}=0.151$ \\
\hline Total protein $\left(\mathrm{g} \mathrm{l}^{-1}\right)$ & $54.15 \pm 5.09$ & $53.91 \pm 5.31$ & $F_{1,18.222}<0.001, \mathrm{p}=0.976$ \\
\hline Initial body temperature $\left({ }^{\circ} \mathrm{C}\right)$ & $29.04 \pm 1.32$ & $28.73 \pm 1.22$ & $F_{1,17.951}=0.160, \mathrm{p}=0.694$ \\
\hline Critical thermal maximum $\left({ }^{\circ} \mathrm{C}\right)$ & $40.51 \pm 1.09$ & $39.84 \pm 1.14$ & $F_{1,17.812}=4.371, \mathrm{p}=0.051$ \\
\hline Initial sand temperature $\left({ }^{\circ} \mathrm{C}\right)$ & $29.40 \pm 1.76$ & $29.06 \pm 1.39$ & $F_{1,17.886}=0.414, \mathrm{p}=0.528$ \\
\hline $\begin{array}{l}\text { Sand temperature at onset of } \\
\text { uncoordinated movements }\left({ }^{\circ} \mathrm{C}\right)\end{array}$ & $33.68 \pm 1.82$ & $32.38 \pm 2.11$ & $F_{1,16.4}=2.050, \mathrm{p}=0.171$ \\
\hline Final sand temperature $\left({ }^{\circ} \mathrm{C}\right)$ & $37.09 \pm 2.07$ & $37.28 \pm 1.74$ & $F_{1,17.705}=0.201, \mathrm{p}=0.660$ \\
\hline
\end{tabular}


for each nest, there was a significant but marginal negative relationship between incubation moisture and $\mathrm{CT}_{\max }\left(F_{1,17.64}=4.67, \mathrm{p}=0.045, \mathrm{R}^{2}=0.078\right)$. Nest ID explained $21.41 \%$ of the variation. There was no difference in the initial body temperature $\left(F_{1,17.951}=\right.$ 0.16, $\mathrm{p}=0.694$, Table 1 ) or initial sand temperature during thermal tolerance testing $\left(F_{1,17.886}=0.414, \mathrm{p}=\right.$ 0.528, Table 1) of hatchlings incubated in either wet or dry conditions. Nest ID explained $79.99 \%$ of the variation in initial body temperature. Additionally, there was no difference in the final sand temperature (i.e. the sand temperature at which $\mathrm{CT}_{\max }$ was reached) between wet and dry incubated hatchlings $\left(F_{1,17.705}=0.201, \mathrm{p}=0.66\right.$, Table 1$)$.

\subsection{Relationships between hatchling hydration, initial body temperature and thermal tolerance}

Irrespective of their incubation conditions, the initial body temperature of hatchlings did not influence their $\mathrm{CT}_{\text {max }}\left(F_{1,79.95}=0.566, \mathrm{p}=0.454, \mathrm{R}^{2}=0.033\right)$ or the time required to reach their $\mathrm{CT}_{\text {max }}\left(F_{1,87.35}=0.153\right.$, $\left.\mathrm{p}=0.697, \mathrm{R}^{2}=0.105\right)$. PCV did not influence hatchling $\mathrm{CT}_{\max }\left(F_{1,85.978}=0.028, \mathrm{p}=0.895, \mathrm{R}^{2}=-0.006\right)$. Hatchlings with higher TP values had lower $\mathrm{CT}_{\max }$ $\left(F_{1,79.99}=4.569, \mathrm{p}=0.036, \mathrm{R}^{2}=0.06\right)$, although this relationship was weak. Nest ID explained 31.36 and $25.15 \%$ of the variation, respectively. There was no relationship between $\mathrm{CT}_{\max }$ and hatching success $\left(F_{1,32.11}=0.83, \mathrm{p}=0.37, \mathrm{R}^{2}=0.02\right)$.
0.017, $\mathrm{R}^{2}=0.31$ ). Nest ID explained $76.3 \%$ (SCL), $79.13 \%$ (SCW) and $72.36 \%$ (mass) of the variation.

\subsection{Nest temperature, incubation duration and thermal tolerance}

The relationship between incubation temperature and duration is non-linear, and the magnitude of the temperature effect on incubation duration becomes greater as the range of temperatures increases (Noble et al. 2018). However, a non-linear model did not explain any additional variation in incubation duration and thus, we evaluated the relationship between incubation temperature and duration in this study linearly. Hatchlings that had shorter incubation durations, and therefore would have incubated at higher temperatures (Matsuzawa et al. 2002), had significantly higher $\mathrm{CT}_{\max }$ compared to hatchlings with longer incubation durations (i.e. lower incubation temperatures) $\left(F_{1,19.564}=6.372, \mathrm{p}=0.02, \mathrm{R}^{2}=\right.$ 0.105) (Fig. 3). Nest ID explained $18.04 \%$ of the variance.

To estimate the incubation temperatures experienced by the hatchlings that we tested, we plotted the relationship between incubation duration and incubation temperature using all of the nests (in both collection rounds) for which we were able to record incubation temperatures (12 nests, Table 2). There was a significant negative linear relationship between incubation duration and mean incubation

\subsection{Effect of body size on hatchling thermal tolerance and hydration}

Longer hatchlings had a higher $\mathrm{CT}_{\text {max }}\left(F_{1,80.151}=9.0284, \mathrm{p}=0.004, \mathrm{R}^{2}=\right.$ $0.057)$, although the relationship was weak. Hatchling mass $\left(F_{1,35.952}=\right.$ 3.7258, $\mathrm{p}=0.061, \mathrm{R}^{2}=0.015$ ) and SCW $\left(F_{1,89.487}=0.437, \mathrm{p}=0.51, \mathrm{R}^{2}=-0.006\right)$ did not influence $\mathrm{CT}_{\max }$. Nest ID explained $31.38,31.26$ and $27.18 \%$ of the variation in $\mathrm{CT}_{\max }$ with $\mathrm{SCL}$, mass and SCW, respectively.

Although SCL $\left(F_{1,87.727}=3.17, \mathrm{p}=\right.$ $\left.0.078, \mathrm{R}^{2}=0.244\right)$ and $\operatorname{SCW}\left(F_{1,82.842}=\right.$ $0.005, p=0.943, R^{2}=0.037$ ) did not influence hatchling initial body temperature, mass did, with heavier hatchlings having lower initial body temperatures $\left(F_{1,82.623}=5.931, \mathrm{p}=\right.$

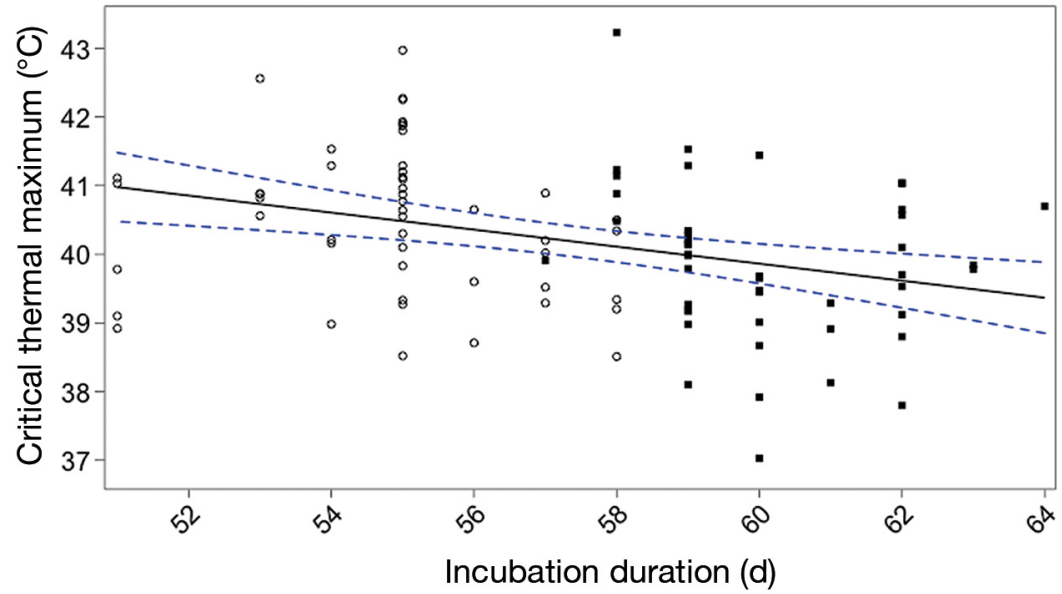

Fig. 3. Relationship between incubation duration and green turtle hatchling critical thermal maximum $\left(\mathrm{CT}_{\max }\right)$. The dashed blue lines represent the $95 \%$ confidence intervals, black squares represent wet nests, and open circles represent dry nests. The relationship between incubation duration and hatchling critical thermal maximum is described by the equation $\mathrm{CT}_{\max }\left({ }^{\circ} \mathrm{C}\right)=47.3-0.12$ $\times d$, where $d=$ incubation duration (days) 
Table 2. Mean \pm SD nest temperatures and incubation durations for all nests that contained temperature probes. We recorded temperature in 10 nests from the first collection (concurrent study which manipulated moisture levels) and 2 nests from the second collection (this study)

\begin{tabular}{|c|c|c|c|c|c|}
\hline $\begin{array}{l}\text { Collection } \\
\text { round }\end{array}$ & $\begin{array}{l}\text { Moisture } \\
\text { level }\end{array}$ & Nest ID & $\begin{array}{c}\text { Moisture concentration } \\
(\% \mathrm{v} / \mathrm{v})\end{array}$ & $\begin{array}{c}\text { Mean nest } \\
\text { temperature }\left({ }^{\circ} \mathrm{C}\right)\end{array}$ & $\begin{array}{l}\text { Incubation } \\
\text { duration (d) }\end{array}$ \\
\hline \multirow[t]{12}{*}{ First } & Wet & S3 & $7.96 \pm 1.35$ & $29.57 \pm 0.78$ & 59 \\
\hline & & S7 & $7.24 \pm 1.25$ & $28.84 \pm 0.72$ & 56 \\
\hline & & S11 & $8.16 \pm 1.10$ & $28.90 \pm 0.74$ & 61 \\
\hline & & S15 & $8.28 \pm 1.11$ & $29.33 \pm 0.85$ & 55 \\
\hline & & S19 & $7.72 \pm 1.45$ & $29.31 \pm 0.61$ & 60 \\
\hline & & Mean & $7.87 \pm 0.41$ & $29.19 \pm 0.31$ & $58.2 \pm 2.6$ \\
\hline & Dry & $\mathrm{S} 4$ & $4.74 \pm 1.06$ & $29.99 \pm 0.80$ & 53 \\
\hline & & S8 & $4.81 \pm 0.88$ & $29.41 \pm 0.55$ & 55 \\
\hline & & $\mathrm{S} 12$ & $4.70 \pm 0.87$ & $29.75 \pm 0.92$ & 54 \\
\hline & & S16 & $4.85 \pm 0.65$ & $29.92 \pm 0.68$ & 57 \\
\hline & & S20 & $4.61 \pm 0.68$ & $29.47 \pm 0.84$ & 53 \\
\hline & & Mean & $4.74 \pm 0.09$ & $29.71 \pm 0.26$ & $54.4 \pm 1.7$ \\
\hline \multirow[t]{2}{*}{ Second } & Wet & S21 & $7.77 \pm 0.92$ & $28.50 \pm 0.78$ & 59 \\
\hline & Dry & S26 & $4.93 \pm 0.80$ & $30.45 \pm 0.96$ & 53 \\
\hline \multirow[t]{2}{*}{ Total } & Mean & Wet nests & $7.86 \pm 0.37$ & $29.08 \pm 0.40$ & $58.3 \pm 2.3$ \\
\hline & & Dry nests & $4.77 \pm 0.11$ & $29.83 \pm 0.38$ & $54.2 \pm 1.6$ \\
\hline
\end{tabular}

temperature $\left(t_{10}=-2.409, \mathrm{p}=0.037, \mathrm{R}^{2}=0.304\right)$ (Fig. 4). Extrapolating from this model using the incubation durations of all hatchlings that were tested for thermal tolerance, we predict that nest temperatures would have ranged from 28 to $31^{\circ} \mathrm{C}$. Of the 2 nests in the second collection for which we did record incubation temperatures, nest S21 (wet conditions) had a mean incubation temperature of $28.5^{\circ} \mathrm{C}$ and an incubation duration of $59 \mathrm{~d}$. Nest S26 (dry conditions) had a mean incubation temperature of $30.45^{\circ} \mathrm{C}$ and an incubation duration of $53 \mathrm{~d}$.
It is likely that incubation duration was influenced indirectly by the cooling effects of our water treatments, as shown by the effect of moisture treatment (wet or dry) on nest temperature and on incubation duration (Fig. 2). As expected, there was a positive relationship between mean incubation moisture and incubation duration $\left(t_{28}=6.56\right.$, $\mathrm{p}<0.0001, \mathrm{R}^{2}=0.59$ ). Additionally, mean moisture concentration explained $40.4 \%$ of the variation in incubation temperature $\left(t_{10}=-2.91, \mathrm{p}=0.015\right.$, $\mathrm{R}^{2}=0.4$ ).

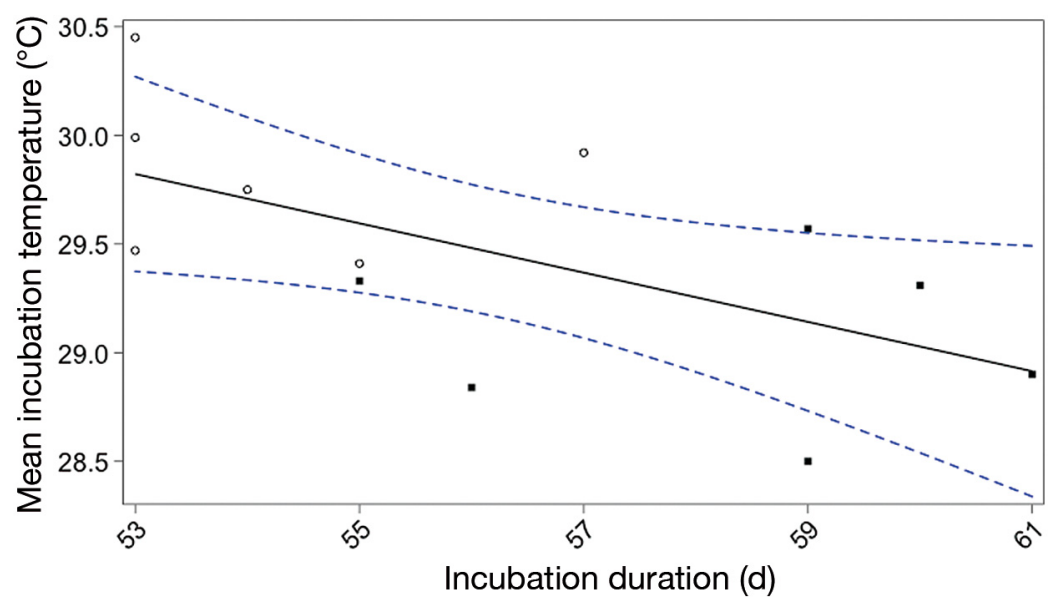

Fig. 4. Relationship between incubation duration and incubation temperature for green turtle nests in this study. The dashed blue lines represent $95 \%$ confidence intervals, black squares represent wet nests, and open circles represent dry nests. The equation for the relationship is mean incubation temperature $\left({ }^{\circ} \mathrm{C}\right)=35.8-0.11 \times d$, where $d=$ incubation duration (days)

\section{DISCUSSION}

The aim of this study was to measure the response of sea turtle hatchling hydration and thermal tolerance to moisture concentrations during incubation. Moisture concentrations during incubation did not influence hatchling hydration levels. The structure, thickness and water permeability of reptile eggs vary considerably, and sea turtles lay 'pliable' eggshells with intermediate water permeability compared to other reptiles (Kusuda et al. 2013). It is possible that in our study, we observed no response of hatchling hydration and thermal tolerance to moisture treatment because our 
treatments did not induce a large enough change in egg water content. This may result from the eggshells altering their permeability to water depending on their hydration state (Lutz et al. 1980, Lillywhite \& Ackerman 1984) or potentially because our eggs contained enough water to survive our chosen treatments (Hewavisenthi et al. 2001). Additionally, mean moisture concentration only had a small influence on hatchling thermal tolerance. Instead, we found that moisture levels altered incubation temperatures, which in turn modified hatchling thermal tolerance. We conclude that considering multiple environmental factors when assessing the role of incubation conditions in determining hatchlings traits is vital.

As a result of some of our temperature probes malfunctioning, we used incubation duration as a proxy for incubation temperature because of the strong and reliable relationship between them (Matsuzawa et al. 2002, Piña et al. 2003, Noble et al. 2018). For example, loggerhead turtle incubation duration decreased from $80 \mathrm{~d}$ at $26^{\circ} \mathrm{C}$ to approximately $50 \mathrm{~d}$ at $32^{\circ} \mathrm{C}$, with temperature explaining $95.7 \%$ of the variation in incubation duration (Matsuzawa et al. 2002). Previous studies that controlled both incubation temperature and moisture generally measured air rather than egg temperature. However, egg temperature can be up to $2^{\circ} \mathrm{C}$ lower than air temperatures, and varies in a moisture-dependent manner (Tezak et al. 2018). Thus, studies that measure air temperatures rather than sand temperature near the egg (e.g. Delmas et al. 2008) may not have detected differences in egg temperature that result from differences in moisture concentrations. Lolavar \& Wyneken (2017) measured both air and sand temperatures when assessing the effect of incubation moisture on sea turtle primary sex ratios. They observed that incubation duration varied among treatments that differed in the amount of evaporative cooling allowed and the temperature of the water applied to eggs during incubation. Thus, Lolavar \& Wyneken (2017) hypothesised that variation in evaporative and direct cooling of the eggs altered embryonic development rate, rather than moisture directly influencing incubation duration. Additionally, when controlling sand temperature, Gatto \& Reina (2020) found no relationship between incubation duration and moisture concentration in green, flatback and olive ridley turtles. Despite moisture explaining more variation in incubation duration than temperature, it is likely that the variation in incubation duration and $\mathrm{CT}_{\max }$ observed in this study resulted from the indirect effects of moisture treatment on nest temperature, rather than from the effects of moisture treatment directly.
The effects of moisture and temperature in our study were interconnected and thus we were unable to completely isolate the individual effects of moisture and temperature on thermal tolerance. However, moisture had little to no effect on any of the hatchling traits that we measured. Incubation duration explained more of the variation in hatchling thermal tolerance than moisture, and temperature had a stronger influence on incubation duration than moisture did. Thus, it is likely that temperature played a larger role in determining hatchling traits than moisture. We suggest that our watering regime altered nest temperatures and that both direct and indirect cooling in wet nests extended incubation duration and lowered hatchling thermal tolerance. Future studies attempting to isolate the effects of moisture and temperature would benefit from examining effects in a laboratory setting where both environmental factors can be controlled. However, our study identifies the important role that moisture plays in determining temperature regimes and influencing hatchling traits, both directly and indirectly in the natural setting.

Hatchlings from warmer nests that had shorter incubation durations had significantly higher $\mathrm{CT}_{\max }$ than hatchlings from cooler nests with longer incubation durations. However, we cannot yet say whether this effect is short-term, i.e. hours or days, or whether hatchlings incubated in warm nests retain a higher $\mathrm{CT}_{\max }$ long-term, i.e. months or years. Additionally, without incubation temperature data, we cannot determine whether hatchling thermal tolerance is the result of acclimation to temperatures at the end of incubation or whether thermal tolerance is the result of developmental changes that occur throughout the entirety of incubation. Studies on adult lizards (Yang et al. 2008, Llewelyn et al. 2017) have shown that $\mathrm{CT}_{\max }$ is generally determined by the recent thermal conditions experienced by individuals. Further studies have shown that incubation temperatures did not have a significant effect on the thermal tolerance of adult lizards raised at a single temperature (Llewelyn et al. 2018, Gunderson et al. 2020), and studies that observed negative relationships between thermal tolerance and incubation temperatures tended to acclimate individuals before testing (Dayananda et al. 2017, Llewelyn et al. 2017). Therefore, it is likely that hatchlings in our study acclimated to nest temperatures during incubation and that a period of acclimation, likely days or weeks, to cooler or warmer temperatures post-emergence would override the effects of incubation temperature (Yang et al. 2008, Abayarathna et al. 2019). 
We also considered the possibility that thermally tolerant hatchlings survive incubation, while less tolerant hatchlings do not. This would result in warm conditions producing fewer hatchlings that are more thermally tolerant and cool conditions producing more hatchlings, but the additional hatchlings from the cool nests would be less resilient to extreme temperatures. However, we did not observe a relationship between hatching success and thermal tolerance, suggesting that incubation temperatures do not select for thermally tolerant hatchlings. Expression of heat shock proteins (HSP; detailed below) increases embryonic thermal tolerance but decreases hatchling thermal tolerance, suggesting that thermally tolerant embryos may have reduced survival post-emergence rather than higher survival (Gao et al. 2014).

The role of acclimation may also explain the differences in $\mathrm{CT}_{\max }$ between our study and that of Drake \& Spotila (2002), who measured the $\mathrm{CT}_{\max }$ of green sea turtle hatchlings from Playa Grande, Costa Rica. In our study, hatchling $\mathrm{CT}_{\max }$ was $40.19^{\circ} \mathrm{C}$ compared to $41.3^{\circ} \mathrm{C}$ for hatchlings from Costa Rica. Costa Rican hatchlings had a mean initial body temperature of $29.7^{\circ} \mathrm{C}$ compared to $29.04^{\circ} \mathrm{C}$ (dry hatchlings) and $28.73^{\circ} \mathrm{C}$ (wet hatchlings) in our study. Malaysian hatchlings in our study are likely to have been acclimated to lower temperatures, as shown by the differences in initial body temperature and because our hatchery was shaded. This potentially explains the reduced ability of hatchlings from our study to tolerate extreme temperatures as shown by their lower $\mathrm{CT}_{\max }$. Beach characteristics are vitally important, with the differences in nest temperature between studies possibly resulting from differences in nest depth, sand type and colour, shading, nest location and differences in climate between the 2 nesting beaches (Hays et al. 2001, Hill et al. 2015). Alternatively, the fact that one study tested $\mathrm{CT}_{\max }$ in air and the other in water may have also led to differences in thermal tolerance, since hatchlings may be more tolerant of elevated temperatures in water than in air. It is possible that sampling hatchlings for blood in our study may have also influenced the thermal tolerance of hatchlings compared to those reported by Drake \& Spotila (2002), possibly through altering the state of hydration of the animals. Lastly, the observed variation in thermal tolerance between this study and that of Drake \& Spotila (2002) may reflect genetic differences between these 2 geographically separate populations. Costa Rican nesting beaches may be hotter than Malaysian beaches leading to
Costa Rican green sea turtle hatchlings naturally exhibiting greater thermal tolerance.

Current research attributes differences in thermal tolerance to varying expression of HSP, both within and among species (Basu et al. 2002, Carmel et al. 2011). Higher temperatures and longer exposures to these temperatures result in increased expression of HSP genes (Tedeschi et al. 2015), with species from warmer regions producing more HSPs at any given temperature than species from cooler regions (Ulmasov et al. 1992). HSP levels can remain elevated for days after heat shock (Lund et al. 2003), potentially in preparation for further heat stress events. While moderate HSP production leads to increased thermal tolerance, excessive production can reduce tolerance (Krebs \& Feder 1998) potentially by interfering with cell function (Feder \& Hofmann 1999). Overexpression of HSP genes during embryonic development can lead to increased embryonic thermal tolerance but also to decreased hatchling thermal tolerance post-emergence (Gao et al. 2014). The warmer incubation temperatures of dry nests in our study may have led to hatchlings from those nests experiencing increased HSP production. Considering that the relationship between TP and $\mathrm{CT}_{\max }$ was weak, our findings suggest that hatchling hydration plays a limited role in determining thermal tolerance, while HSP production or efficacy may be limited in individuals with higher TP concentrations (Dill et al. 2011). However, previous studies have found that extreme levels of dehydration can alter thermal tolerance in reptiles (Plummer et al. 2003). Thus, hydration may influence sea turtle hatchling thermal tolerance, although not at the levels we measured.

Maternal effects can also have considerable influence on hatchling traits (Wallace et al. 2006, Andrews 2018). While the influence of maternal effects on hatchling morphology is well established in reptiles and birds (Finkler 1999, Wallace et al. 2006), its role in determining other hatchling traits, such as sex, is less certain (Radder 2007). Maternal identity may influence thermal tolerance genetically (Urban et al. 2014) or by altering yolk quantity and quality (Warner \& Lovern 2014). In our study, nest ID explained considerable variation in thermal tolerance $(21.7 \%)$, PCV $(31.4 \%)$ and TP $(25.2 \%)$ with moisture treatment. While this suggests that maternal identity is playing an important role in determining hatchling thermal tolerance, the mechanisms behind this effect require further investigation. In particular, future studies should investigate the potential effects of yolk and albumin composition (i.e. relative protein 
and lipid concentrations) and genetics on TP, specifically HSPs.

Currently, shading and watering nests are popular management techniques for decreasing nest temperatures and minimising embryonic mortality on nesting beaches (Hill et al. 2015). While this practice may decrease nest temperatures and maximise hatching success, it could have negative repercussions for hatchlings during emergence and dispersal. The decreased nest temperatures caused by higher moisture levels or increased shade could lead to the production of hatchlings with lower thermal tolerance that may have to crawl across hot sand to reach the ocean. This could shift mortality events from inside the nest during development to the beach surface during emergence and dispersal, instead of increasing hatchling recruitment. Additionally, hot surface temperatures can limit the ability of hatchlings to escape the nest during emergence (Moran et al. 1999, Drake \& Spotila 2002), and reduced hatchling thermal tolerance may result in decreased emergence success. However, the upper thermal limit of developing embryos $\left(35^{\circ} \mathrm{C}\right)$ is considerably less than the $\mathrm{CT}_{\max }$ of hatchlings $\left(40.19^{\circ} \mathrm{C}\right.$ in our study), suggesting that embryonic mortality is likely to become problematic before hatchling mortality. Additionally, hatchlings generally emerge during the night when sand temperatures are cooler, although some nests do emerge during the day or early evening when surface sand is still hot (Witherington et al. 1990). Future management interventions involving watering or shading nests may therefore require reduced nest temperatures to maximise hatching success, yet may also result in increased mortality of hatchlings during dispersal, particularly in nests that emerge during the day. The negative effects of this trade-off will be minimal in projects that guard hatchlings after they are released from hatcheries but may reduce hatchling survival when these management interventions are made on natural beaches and nests. Additionally, the negative effects of reduced thermal tolerance on hatchling survival will be minimal in nests that emerge at night or only disperse a short distance from nest to ocean.

Current projections suggest that embryonic mortality is the largest threat to sea turtle populations globally (Laloë \& Hays 2017, Monsinjon et al. 2019). These projections do not generally consider hatchling mortality on the nesting beach, and therefore, the number of hatchlings projected to survive incubation may be much higher than the number of hatchlings that actually reach the ocean. As sand temperatures continue to warm, the number of hatchlings surviving dispersal from the nest to the ocean may decrease. However, if hatchling thermal tolerance increases with warmer sand temperatures, the discrepancy between the number of hatchlings that successfully hatch and that enter the ocean may not increase as rapidly as previously thought. Although hatching success is a key indicator of population viability, the number of hatchlings that successfully hatch becomes irrelevant if few or none of those hatchlings are physiologically capable of surviving post-emergence. Future projections should consider not only embryonic thermal tolerance under future sand and nest temperatures but also hatchling thermal tolerance, to refine current estimates of hatchling recruitment and survival.

In conclusion, our study showed that moisture concentrations during incubation did not directly influence hatchling hydration or thermal tolerance. Rather, moisture levels altered nest temperatures, and it was nest temperature that determined hatchling thermal tolerance. Hatchlings acclimated to nest temperatures, with warmer nests producing hatchlings with higher $\mathrm{CT}_{\max }$. Hatchling hydration and body size also influenced thermal tolerance, although both relationships were weak and require further investigation. Future studies will need to consider how a wider range of temperatures influences thermal tolerance, particularly at temperatures near the $35^{\circ} \mathrm{C}$ upper thermal limit for embryos. Furthermore, future studies should investigate whether maternal identity influences thermal tolerance, at what stage during incubation temperature influences thermal tolerance, and whether temperature effects can be overridden by acclimating hatchlings postemergence or acclimating embryos during the final days of incubation.

Acknowledgements. Thanks to Bella Jack and the staff at Lang Tengah Turtle Watch for your support and enthusiasm during data collection. Thanks also to Dr. Mohd Uzair Rusli for help securing permits and to Jeanette Wyneken for comments on this manuscript. C.R.G. was supported by an Australian Government Research Training Program (RTP) scholarship. This project was funded with support from a Monash University cross-campus initiative grant.

\section{LITERATURE CITED}

Abayarathna T, Murray BR, Webb JK (2019) Higher incubation temperatures produce long-lasting upward shifts in cold tolerance, but not heat tolerance, of hatchling geckos. Biol Open 8:bio042564

Andrews RM (2018) Developmental plasticity in reptiles: insights into thermal and maternal effects on chameleon phenotypes. J Exp Zool A Ecol Integr Physiol 329: 298-307 
Basu N, Todgham A, Ackerman P, Bibeau M, Nakano K, Schulte P, Iwama GK (2002) Heat shock protein genes and their functional significance in fish. Gene 295: 173-183

Bates D, Mächler M, Bolker B, Walker S (2015) Fitting linear mixed-effects models using lme4. J Stat Softw 67:1-48

Binckley CA, Spotila JR, Wilson KS, Paladino FV (1998) Sex determination and sex ratios of Pacific leatherback turtles, Dermochelys coriacea. Copeia 1998:291-300

Booth DT (2017) Influence of incubation temperature on sea turtle hatchling quality. Integr Zool 12:352-360

Booth DT, Evans A (2011) Warm water and cool nests are best. How global warming might influence hatchling green turtle swimming performance. PLOS ONE 6:e23162

Booth DT, Dunstan A, Bell I, Reina R, Tedeschi J (2020) Low male production at the world's largest green turtle rookery. Mar Ecol Prog Ser 653:181-190

Bower DS, Hodges KM, Georges A (2013) Salinity of incubation media influences embryonic development of a freshwater turtle. J Comp Physiol B Biochem Syst Environ Physiol 183:235-241

* Burgess EA, Booth DT, Lanyon JM (2006) Swimming performance of hatchling green turtles is affected by incubation temperature. Coral Reefs 25:341-349

Carmel J, Rashkovetsky E, Nevo E, Korol A (2011) Differential expression of small heat shock protein genes Hsp23 and Hsp40, and heat shock gene Hsr-omega in fruit flies (Drosophila melanogaster) along a microclimatic gradient. J Hered 102:593-603

Caut S, Guirlet E, Girondot M (2010) Effect of tidal overwash on the embryonic development of leatherback turtles in French Guiana. Mar Environ Res 69:254-261

* Cavallo C, Dempster T, Kearney MR, Kelly E, Booth D, Hadden KM, Jessop TS (2015) Predicting climate warming effects on green turtle hatchling viability and dispersal performance. Funct Ecol 29:768-778

* Dayananda B, Murray BR, Webb JK (2017) Hotter nests produce hatchling lizards with lower thermal tolerance. J Exp Biol 220:2159-2165

* Delmas V, Bonnet X, Girondot M, Prévot-Julliard AC (2008) Varying hydric conditions during incubation influence egg water exchange and hatchling phenotype in the redeared slider turtle. Physiol Biochem Zool 81:345-355

Will KA, Ghosh K, Schmit JD (2011) Physical limits of cells and proteomes. Proc Natl Acad Sci USA 108:17876-17882

Drake DL, Spotila JR (2002) Thermal tolerances and the timing of sea turtle hatchling emergence. J Therm Biol 27: 71-81

Elphick MJ, Shine R (1998) Longterm effects of incubation temperatures on the morphology and locomotor performance of hatchling lizards (Bassiana duperreyi, Scincidae). Biol J Linn Soc 63:429-447

Feder ME, Hofmann GE (1999) Heat-shock proteins, molecular chaperones, and the stress response: evolutionary and ecological physiology. Annu Rev Physiol 61:243-282

Finkler MS (1999) Influence of water availability during incubation on hatchling size, body composition, desiccation tolerance, and terrestrial locomotor performance in the snapping turtle Chelydra serpentina. Physiol Biochem Zool 72:714-722

Fisher LR, Godfrey MH, Owens DW (2014) Incubation temperature effects on hatchling performance in the loggerhead sea turtle (Caretta caretta). PLOS ONE 9:e114880

Foley KE (2017) Florida beaches are getting so hot that baby sea turtles are cooking alive. Quartz. https://qz.com/ 1006306/climate-change-is-killing-sea-turtles-by-makingbeaches-too-hot-for-the-newly-hatched-to-survive/

Freedberg S, Stumpf AL, Ewert MA, Nelson CE (2004) Developmental environment has long-lasting effects on behavioural performance in two turtles with environmental sex determination. Evol Ecol Res 6:739-747

French NA (1994) Effect of incubation temperature on the gross pathology of turkey embryos. Br Poult Sci 35: 363-371

* Fuentes MMPB, Hamann M, Limpus CJ (2010) Past, current and future thermal profiles of green turtle nesting grounds: implications from climate change. J Exp Mar Biol Ecol 383:56-64

*Fuentes MMPB, Fish MR, Maynard JA (2012) Management strategies to mitigate the impacts of climate change on sea turtle's [sic] terrestrial reproductive phase. Mitig Adapt Strategies Glob Change 17:51-63

*Gao J, Zhang W, Dang W, Mou Y, Gao Y, Sun BJ, Du WG (2014) Heat shock protein expression enhances heat tolerance of reptile embryos. Proc R Soc B 281:20141135

*Gatto CR, Reina RD (2020) Sea turtle hatchling locomotor performance: incubation moisture effect, ontogeny and species-specific patterns. J Comp Physiol B Biochem Syst Environ Physiol 190:779-793

Godfrey MH, Mrosovsky N (2006) Pivotal temperature for green sea turtles, Chelonia mydas, nesting in Suriname. Herpetol J 16:55-61

*Godley BJ, Broderick AC, Glen F, Hays GC (2002) Temperature-dependent sex determination of Ascension Island green turtles. Mar Ecol Prog Ser 226:115-124

*Gunderson AR, Fargevieille A, Warner DA (2020) Egg incubation temperature does not influence adult heat tolerance in the lizard Anolis sagrei. Biol Lett 16:20190716

Hays GC, Ashworth JS, Barnsley MJ, Broderick AC and others (2001) The importance of sand albedo for the thermal conditions on sea turtle nesting beaches. Oikos 93:87-94

Hewavisenthi S, Parmenter CJ, Gatten R Jr (2001) Influence of incubation environment on the development of the flatback turtle (Natator depressus). Copeia 2001: 668-682

Hill JE, Paladino FV, Spotila JR, Tomillo PS (2015) Shading and watering as a tool to mitigate the impacts of climate change in sea turtle nests. PLOS ONE 10:e0129528

*Howard R, Bell I, Pike DA (2014) Thermal tolerances of sea turtle embryos: current understanding and future directions. Endang Species Res 26:75-86

Krebs RA, Feder ME (1998) Hsp70 and larval thermotolerance in Drosophila melanogaster: How much is enough and when is more too much? J Insect Physiol 44: 1091-1101

Kusuda S, Yasukawa Y, Shibata H, Saito T, Doi O, Ohya Y, Yoshizaki N (2013) Diversity in the matrix structure of eggshells in the Testudines (Reptilia). Zool Sci 30: 366-374

Kuznetsova A, Brockhoff PB, Christensen RHB (2017) lmerTest package: tests in linear mixed effects models. J Stat Softw 82:1-26

Laloë JO, Hays G (2017) Can sea turtles cope with climate change? Australas Sci 38:17

* Laloë JO, Cozens J, Renom B, Taxonera A, Hays GC (2014) Effects of rising temperature on the viability of an important sea turtle rookery. Nat Clim Change 4:513-518

Lillywhite HB, Ackerman RA (1984) Hydrostatic pressure, shell compliance and permeability to water vapor in flexible-shelled eggs of the colubrid snake Elaphe obsoleta. 
In: Seymour RS (ed) Respiration and metabolism of embryonic vertebrates. Perspectives in vertebrate science, Vol 3. Springer, Dordrecht, p 121-135

* Llewelyn J, Macdonald S, Hatcher A, Moritz C, Phillips BL (2017) Thermoregulatory behaviour explains countergradient variation in the upper thermal limit of a rainforest skink. Oikos 126:748-757

* Llewelyn J, Macdonald SL, Moritz C, Martins F, Hatcher A, Phillips BL (2018) Adjusting to climate: acclimation, adaptation and developmental plasticity in physiological traits of a tropical rainforest lizard. Integr Zool 13: 411-427

Lodge J (2017) Turtle hatchlings dying in extreme heat at Mon Repos. www.abc.net.au/news/2017-02-04/monrepos-turtles-hurting-in-heatwave-qld/8230036 (accessed 8 March 2018)

Kolavar A, Wyneken J (2017) Experimental assessment of the effects of moisture on loggerhead sea turtle hatchling sex ratios. Zoology 123:64-70

Lund SG, Lund ME, Tufts BL (2003) Red blood cell Hsp 70 mRNA and protein as bio-indicators of temperature stress in the brook trout (Salvelinus fontinalis). Can J Fish Aquat Sci 60:460-470

KLutterschmidt WI, Hutchison VH (1997) The critical thermal maximum: data to support the onset of spasms as the definitive end point. Can J Zool 75:1553-1560

* Lutz PL, Bentley TB, Harrison KE, Marszalek DS (1980) Oxygen and water vapour conductance in the shell and shell membrane of the American crocodile egg. Comp Biochem Physiol Part A Physiol 66:335-338

Mader D, Rudloff E (2006) Emergency and critical care. In: Mader D (ed) Reptile medicine and surgery, Book 2. Saunders/Elsevier, St. Louis, MO, p 533-548

Matsuzawa Y, Sato K, Sakamoto W, Bjorndal K (2002) Seasonal fluctuations in sand temperature: effects on the incubation period and mortality of loggerhead sea turtle (Caretta caretta) pre-emergent hatchlings in Minabe, Japan. Mar Biol 140:639-646

Monsinjon JR, Wyneken J, Rusenko K, López-Mendilaharsu $M$ and others (2019) The climatic debt of loggerhead sea turtle populations in a warming world. Ecol Indic 107: 105657

Moran KL, Bjorndal KA, Bolten AB (1999) Effects of the thermal environment on the temporal pattern of emergence of hatchling loggerhead turtles Caretta caretta. Mar Ecol Prog Ser 189:251-261

* Murray CB, McPhail JD (1988) Effect of incubation temperature on the development of five species of Pacific salmon (Oncorhynchus) embryos and alevins. Can J Zool 66:266-273

Noble DWA, Stenhouse V, Schwanz LE (2018) Developmental temperatures and phenotypic plasticity in reptiles: a systematic review and meta-analysis. Biol Rev Camb Philos Soc 93:72-97

*Piña CI, Larriera A, Cabrera MR (2003) Effect of incubation temperature on incubation period, sex ratio, hatching success, and survivorship in Caiman latirostris (Crocodylia, Alligatoridae). J Herpetol 37:199-202

Plummer MV, Williams BK, Skiver MM, Carlyle JC (2003) Effects of dehydration on the critical thermal maximum of the desert box turtle (Terrapene ornata luteola). J Herpetol 37:747-750

R Core Team (2020) R: a language and environment for statistical computing. R Foundation for Statistical Computing, Vienna. www.r-project.org
Radder RS (2007) Maternally derived egg yolk steroid hormones and sex determination: review of a paradox in reptiles. J Biosci (Bangalore) 32:1213-1220

Reina RD, Mayor PA, Spotila JR, Piedra R, Paladino FV (2002) Nesting ecology of the leatherback turtle, Dermochelys coriacea, at Parque Nacional Marino las Baulas, Costa Rica: 1988-1989 to 1999-2000. Copeia 2002: 653-664

* Santidrián Tomillo P, Saba VS, Blanco GS, Stock CA, Paladino FV, Spotila JR (2012) Climate driven egg and hatchling mortality threatens survival of Eastern Pacific leatherback turtles. PLOS ONE 7:e37602

Santidrián Tomillo P, Oro D, Paladino FV, Piedra R, Sieg AE, Spotila JR (2014) High beach temperatures increased female-biased primary sex ratios but reduced output of female hatchlings in the leatherback turtle. Biol Conserv 176:71-79

Santidrián Tomillo P, Genovart M, Paladino FV, Spotila JR, Oro D (2015) Climate change overruns resilience conferred by temperature-dependent sex determination in sea turtles and threatens their survival. Glob Change Biol 21:2980-2988

* Tedeschi JN, Kennington WJ, Berry O, Whiting S, Meekan M, Mitchell NJ (2015) Increased expression of Hsp70 and Hsp90 mRNA as biomarkers of thermal stress in loggerhead turtle embryos (Caretta caretta). J Therm Biol 47:42-50

Tezak BM, Sifuentes-Romero I, Wyneken J (2018) A new approach for measuring temperature inside turtle eggs. J Exp Biol 221:jeb188698

*Ulmasov KA, Shammakov S, Karaev K, Evgen'ev MB (1992) Heat shock proteins and thermoresistance in lizards. Proc Natl Acad Sci USA 89:1666-1670

* Urban MC, Richardson JL, Freidenfelds NA (2014) Plasticity and genetic adaptation mediate amphibian and reptile responses to climate change. Evol Appl 7:88-103

V Valverde RA, Wingard S, Gómez F, Tordoir MT, Orrego CM (2010) Field lethal incubation temperature of olive ridley sea turtle Lepidochelys olivacea embryos at a mass nesting rookery. Endang Species Res 12:77-86

W Wallace BP, Sotherland PR, Spotila JR, Reina RD, Franks BF, Paladino FV (2004) Biotic and abiotic factors affect the nest environment of embryonic leatherback turtles, Dermochelys coriacea. Physiol Biochem Zool 77:423-432

* Wallace BP, Sotherland PR, Tomillo PS, Bouchard SS, Reina RD, Spotila JR, Paladino FV (2006) Egg components, egg size, and hatchling size in leatherback turtles. Comp Biochem Physiol A Mol Integr Physiol 145:524-532

*Warner DA, Lovern MB (2014) The maternal environment affects offspring viability via an indirect effect of yolk investment on offspring size. Physiol Biochem Zool 87: 276-287

Williamson SA, Evans RG, Reina RD (2017) When is embryonic arrest broken in turtle eggs? Physiol Biochem Zool 90:523-532

Witherington BE, Bjorndal KA, McCabe CM (1990) Temporal pattern of nocturnal emergence of loggerhead turtle hatchlings from natural nests. Copeia 1990: 1165-1168

*Yang J, Sun YY, An H, Ji X (2008) Northern grass lizards (Takydromus septentrionalis) from different populations do not differ in thermal preference and thermal tolerance when acclimated under identical thermal conditions. J Comp Physiol B Biochem Syst Environ Physiol 178: 343-349

Submitted: September 9, 2020

Accepted: January 4, 2021

Proofs received from author(s): March 23, 2021 